\title{
A Novel Approach for Multiple DG Allocation in Real Distribution System
}

\author{
Sarfaraz Nawaz ${ }^{* 1}$, Dr. Ajay Kumar Bansal ${ }^{* 2}$, Dr. Mahaveer Prasad Sharma ${ }^{\# 3}$ \\ *Poornima University Jaipur, India \\ ${ }^{1}$ eesarfaraz1983@gmail.com, ${ }^{2}$ ajaykb007@gmail.com \\ ${ }^{\#}$ RVPNL, Jaipur, India \\ ${ }^{3}$ mahavir_sh@rediffmail.com
}

\begin{abstract}
A novel approach has been proposed in this paper for optimal placement of DG units in radial distribution system. An objective function is formulated to find out the optimal size, quantity and position of DG units for real power loss reduction and voltage profile enhancement. A new mathematical expression, Power Voltage Sensitivity Constant (PVSC), has been proposed to solve the allocation problem. The total size of DG units is also restricted up to $50 \%$ of total load of system. A novel index is also proposed which incorporates level of DG penetration and \% reduction in real power losses. The results of the proposed technique are validated on standard IEEE 33 bus system and 130 bus real distribution system of Jamawaramgarh, Jaipur city. The obtained results are compared with latest optimization techniques to show the effectiveness and robustness of the proposed approach.
\end{abstract}

Keywords: Radial Distribution system (RDS), PVSC, DGPI, Power loss, DG units

\section{INTRODUCTION}

As per Indian scenario significant part of the system losses (around 21\%) are distribution losses. Therefore, myriads of efforts have been made for the reduction of losses in distribution networks like as: optimal capacitor placement and distributed generation usage. DG units came into picture from last two decades due to the development in DG technologies and deregulation of electricity market in addition to other factors like economical and regulatory changes in distribution system. DG can utilize the power of both renewable and nonrenewable energy sources. Sources like wind, solar, geothermal, small hydro and biomass and cogeneration come in the category of renewable energy, while reciprocating engines, fuel cell, gas turbines and micro turbines are the part of non-renewable energy sources. Optimal DG Allocation (OPDG) can enhance the system performance with the point of view of voltage stability, minimal system losses and flows, better power quality and improved reliability of power supply. The problem in DG allocation is to find the optimal location, size and quantity of DG units to be installed into existing distribution networks that can satisfy all the operating constraints of electrical network. The OPDG is a complex heterogeneous nonlinear problem of optimization. The problem of optimal DG allocation has therefore drawn the concern of many researchers in last fifteen years.

G. Levitin [1] presented a solution by combining genetic algorithm and fast energy loss method. The solution was using fast energy losses that based on the daily load curve calculates the losses and does not require to compute load flow to evaluate the annual energy losses. Kyu-Ho Kim et. al. [2] adopted hybridized method to determine optimal location of DGs along with their capacities in distribution networks. The authors combined the Genetic algorithm with theory of fuzzy set. M. Gandomkar et. al. [3] suggested a method that works as a new hybridized algorithm for deciding the optimal DG site and size in medium voltage systems. The GA was correlated to Simulated Annealing (SA) metaheuristic methods and employed for DG allocation. N. Acharya et. al. [4] presented an analytical method to calculate the optimal capacity of DG. A direct equation derived from the sensitivity factor equation calculates the optimal size of DG corresponding with each network bus. S. Kamalinia, et. al. [5] proposed a solution for the problem of optimal DG placement developed by using a technique of MADM (Multi-Attribute Decision Making) and Genetic algorithm. To determine the optimal capacity and location of DG units, authors used Analytic Hierarchy Process (AHP) along with Data Envelopment Analysis (DEA) as the technique of multi attribute decision-making. M.A. Kashem et. al. [6] established a deterministic methodology that was based on the SQP algorithm for determining the optimal location and size of DG in distribution network systems. Wichit and Deependra Singh et. al. [7] introduced a technique using GA for placement of distributed generation. Three types of loading conditions (peak, medium and low) were examined. M. Abbagana et. al. [8] derived a methodology based on the technique of Differential Evolution to calculate the size and location of DG in distribution network while meeting all the constraints of optimality. The authors presented decision making techniques to find the solution for OPDG. M. Sedighi et. al. [9] evaluated the optimal location and capacity of single and multiple DGs by adopting PSO method. S. Nawaz et al. [10] presented sensitivity analysis technique and tested it on 33 bus system at different loading condition. Rajkumar Viral et.al [11] proposed an analytical approach to determine the best position and size of DG units in balanced distribution system to reduce real power. 
In this paper, a novel approach to solve allocation of multiple DG units problem is presented for active power loss minimization and voltage profile enhancement. A new mathematical expression is formulated that is called PVSC (Power Voltage Sensitivity Constant). This constant evaluate size and location of DG units at the same time. The total size of DG units is also restricted up to $50 \%$ of total load of system, so that less size of DG units produce maximum loss reduction. A new index, DG penetration index (DGPI), is also introduced here. This index gives the value of percentage loss reduction for unit DG size. This index is used to show the superiority of the proposed approach over other ones. Standard 33 bus distribution system and 130 bus practical system of Jamawaramgarh area of Jaipur city are used to validate the above mentioned approach. The obtain results showed that proposed approach gives better outcome than other approaches mentioned in this paper.

\section{PROBLEM FORMULATION}

The objective of the paper is the minimization in active power loss of radial distribution system to its lowest value. This is achieved by installing the DG units of appropriate size at optimal location. The operating constraints of the problem are divided into equality and inequality constraints.

Mathematically, the DG placement problem can be formulated as a constrained nonlinear optimization model [12]:

$$
\text { Minimize }\left(\mathrm{P}_{\text {Loss }}\right)
$$

Subjected to: $\quad \mathrm{k} 1(\mathrm{x}, \mathrm{z})=0$

$$
\mathrm{k} 2(\mathrm{x}, \mathrm{z}) \leq 0
$$

$\mathrm{k} 1(\mathrm{x}, \mathrm{z})$ and $\mathrm{k} 2(\mathrm{x}, \mathrm{z})$ are the set of equality and inequality constraints, respectively. Where, $\mathrm{x}$ is the state variables and $\mathrm{z}$ is the control variables. The control variables are power outputs of DG (P and Q). The state variables are bus voltage and line power flows.

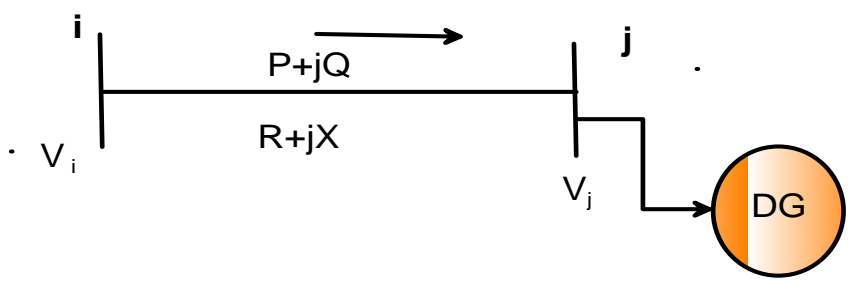

Fig.1. DG connected radial distribution network of $i-j$ bus

The figure 1 shows the line diagram of two bus system. The DG unit is connected at bus $\mathrm{j}$. The distribution network power loss of above system for $\mathrm{n}$ bus is calculated by using:

$$
P_{\text {Loss }}=\sum_{i=1}^{n} \sum_{j=1}^{n} R \frac{\left|V_{i}\right|^{2}+\left|V_{j}\right|^{2}-2\left|V_{i}\right|\left|V_{j}\right| \cos \delta_{i j}}{Z^{2}}
$$

(a) Equality Constraints:

The arithmetical summation of all incoming and outgoing powers together with power losses for distribution system and power generated by DG units should be equal to zero.

(b) Inequality Constraints:

(i) The injected power by each DG units is restricted by its maximum and minimum limits as,

$$
\begin{aligned}
P_{D G j}^{\min } & \leq P_{D G j} \leq P_{D G j}^{\max } \\
Q_{D G j}^{\min } \leq Q_{D G j} & \leq Q_{D G j}^{\max }
\end{aligned}
$$

(ii) Bus voltage limits $\quad V_{\min } \leq V_{i} \leq 1.0 \mathrm{pu}$

(iii) The feeder should not go beyond the thermal limit of the line.

Where,

$\mathrm{R}$ : Line resistance between bus $\mathrm{i}$ and $\mathrm{j} ; \mathrm{X}$ : Line reactance between bus $\mathrm{i}$ and $\mathrm{j} ; \mathrm{Z}$ : Line impedance;

$\mathrm{V}_{\mathrm{i}}$ : Magnitude of voltage at bus i; $\mathrm{V}_{\mathrm{j}}$ : Magnitude of voltage at bus $\mathrm{j} ; \mathrm{V}_{\text {min }}$ : Minimum bus voltage

$\delta_{\mathrm{i}}$ : Angle of voltage at bus $\mathrm{i} ; \delta_{\mathrm{j}}$ : Angle of voltage at bus $\mathrm{j} ; \mathrm{P}$ and Q: Active and reactive power flow from bus $\mathrm{i}$ to $\mathrm{j}$ 


\section{PROPOSED APPROACH}

\section{A. Power Voltage Sensitivity Constant (PVSC)}

In this paper allocation of DG unit problem is done by analytical technique. The Power Voltage Sensitivity Constant (PVSC) is proposed to determine the size and position of DG units. This constant takes active power loss and voltage limits in account and suggest the optimal location of the DG.

PVSC $=\frac{V_{\max }}{V_{\min }}+\frac{\text { Pdgloss }}{\text { Prealloss }}(3)$

Where,

$\mathrm{P}_{\text {realloss }}$ is the base case real power loss.

$\mathrm{P}_{\text {dgloss }}$ is the real power loss after DG placement at $\mathrm{i}^{\text {th }}$ bus.

$\mathrm{V}_{\max }$ is maximum bus voltage in pu after DG placement at $\mathrm{i}^{\text {th }}$ bus. (Always $1 \mathrm{pu}$ )

$\mathrm{V}_{\min }$ is minimum bus voltage in pu after DG placement at $\mathrm{i}^{\text {th }}$ bus.

For optimal placement of DG units the value of PVSC should be minimum. Computational procedure for proposed analytical method is explained below.

Step 1: Run the load flow program calculate value of $\mathrm{P}_{\text {realloss }}$.

Step 2: Set 5\% DG penetration level and run load flow program.

Step 3: Compute $\mathrm{P}_{\text {dgloss }}$ of the system and "PVSC" values for each bus using eq. 3 .

Step 4: Now vary DG penetration in small step and compute $P_{\text {dgloss }}$.

Step 5: Store the size of DGs which gives least amount of $P_{\text {dgloss. }}$.

Step 6: The bus, which has least "PVSC" value, will be the optimal position of DG unit.

Step 7: Repeat Steps 4 to 6 to find more location of DGs.

B. DG penetration Index (DGPI)

Most of the researchers did not consider DG penetration in their research. In many practical cases along with economic constraints the size of DG units are not pragmatic. In their paper the size of DG unit is very high. But the high size of DG unit will lead to high cost of the system.

In this paper a novel index, called DG penetration index, is proposed. The DGPI gives the \% power loss reduction for unit size of DG.

DGPI $=\frac{(\% \text { power loss reduction })}{\text { Total DG size }}$

Hence, for optimal allocation of DG units the value of DGPI should be maximum.

\section{RESULTS}

The proposed technique has been tested on standard 33 test distribution system and 130 bus real distribution system of Jamwaramgarh area of Jaipur city. Three different loading conditions i.e. light load (50\%), nominal load $(100 \%) \&$ heavy load $(160 \%)$ have also been considered to validate the results.

Test system-II

The IEEE 33 bus radial distribution has total load of $3.715 \mathrm{MW}$ and 2.30 MVAr. The base network power loss is $202.68 \mathrm{~kW}$ [13]. The base values are $12.66 \mathrm{kV}$ and 100 MVA. Before and after DG placement results at different load levels are shown in table I.

TABLE I. DG Allocation on 33-Bus Test System at Different Load Levels

\begin{tabular}{|l|l|c|c|c|}
\hline \multirow{4}{*}{} & \multirow{2}{*}{ Indices } & \multicolumn{3}{|c|}{ Load level } \\
\cline { 3 - 5 } & $\begin{array}{c}\text { Light load } \\
\mathbf{( 0 . 5 )}\end{array}$ & $\begin{array}{c}\text { Nominal load } \\
\mathbf{( 1 . 0 )}\end{array}$ & $\begin{array}{c}\text { Heavy load } \\
\mathbf{( 1 . 6 )}\end{array}$ \\
\hline \multirow{4}{*}{ Without DG } & Power Loss in $\mathrm{kW}$ & 47 & 202.7 & 575.36 \\
\cline { 2 - 5 } & $\mathrm{V}_{\min }$ in pu & 0.9583 & 0.9131 & 0.853 \\
\hline \multirow{5}{*}{ With DG } & DG size in kW [bus no.] & $297[16]$ & $595[16]$ & $830[16]$ \\
& & $316[32]$ & $630[32]$ & $1010[32]$ \\
& & $240[30]$ & $500[30]$ & $720[30]$ \\
\cline { 2 - 5 } & Total DG size in $\mathrm{kW}$ & 853 & 1725 & 2560 \\
\cline { 2 - 5 } & Real Power losses in $\mathrm{kW}$ & 21.4 & 88.5 & 244 \\
\cline { 2 - 5 } & Min. bus voltage in p.u. & 0.983 & 0.967 & 0.937 \\
\cline { 2 - 5 } & \% Loss reduction & $\mathbf{5 4 . 4 6}$ & $\mathbf{5 6 . 3 3}$ & $\mathbf{5 7 . 6}$ \\
\hline
\end{tabular}


First three candidate buses are selected for DG allocation. The real power losses are reduced to $21.4 \mathrm{~kW}, 88.5$ $\mathrm{kW}$ and $244 \mathrm{~kW}$ on light, nominal and heavy loading condition respectively. The bus voltages are also enhanced.

The results of proposed analytical approach for 33 bus system at nominal load level is compared with Mixed Integer Non-Linear Programming (MINLP) [14], hybridization of analytical method and heuristic search method [15], BAT algorithm [16] and Bacterial Foraging Optimization Algorithm (BFOA) [17]. It is observed from table II, that the proposed approach has maximum value of DGPI than other techniques. This shows the credibility of proposed method.

TABLE II. Comparison of Results of DG Allocation for 33-Bus at Nominal Load

\begin{tabular}{|l|l|l|l|l|}
\hline Techniques & Total DG size (kW) & $\mathbf{V}_{\text {min }}(\mathbf{p u )}$ & \% Loss reduction & DGPI \\
\hline MINLP (2014) [14] & 2940 & - & 65.50 & 0.022 \\
\hline Hybrid (2016) [15] & 2870 & - & 65.45 & 0.022 \\
\hline BAT (2016) [16] & 2721 & 0.96 & 64.42 & 0.023 \\
\hline BFOA (2016) [17] & 2742 & 0.967 & 65.14 & 0.023 \\
\hline Proposed & $\mathbf{1 7 2 5}$ & $\mathbf{0 . 9 6 7}$ & $\mathbf{5 6 . 3 3}$ & $\mathbf{0 . 0 3 2}$ \\
\hline
\end{tabular}

Figure 2 shows the voltage profile before and after DG placement at different bus for 33 bus distribution system (at nominal load). The bus voltages are improved in proposed method.

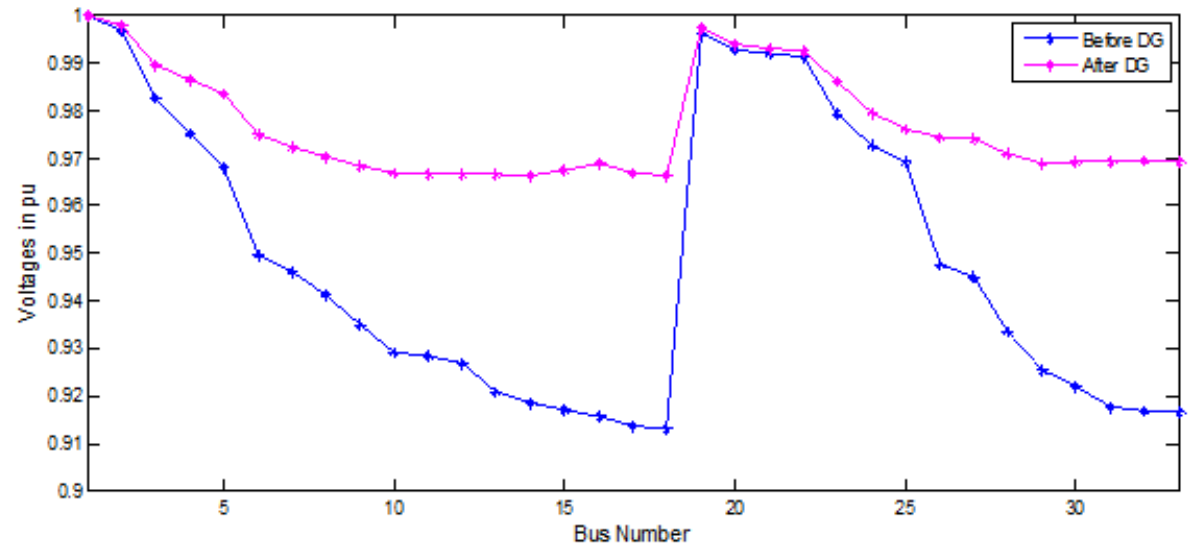

Fig 2: Voltage profile of 33 bus system (nominal load)

\section{B. Test system-II}

The system under consideration is $11 \mathrm{kV}, 130$ bus radial distribution system of Jamwaramgarh area, Jaipur city as shown in figure 2 . The system load is $1878 \mathrm{~kW}$ and $1415 \mathrm{kVAr}$. The line and load data are given in appendix. The real power loss of the system is $335 \mathrm{~kW}$ and minimum bus voltage is 0.825 pu without any compensation.

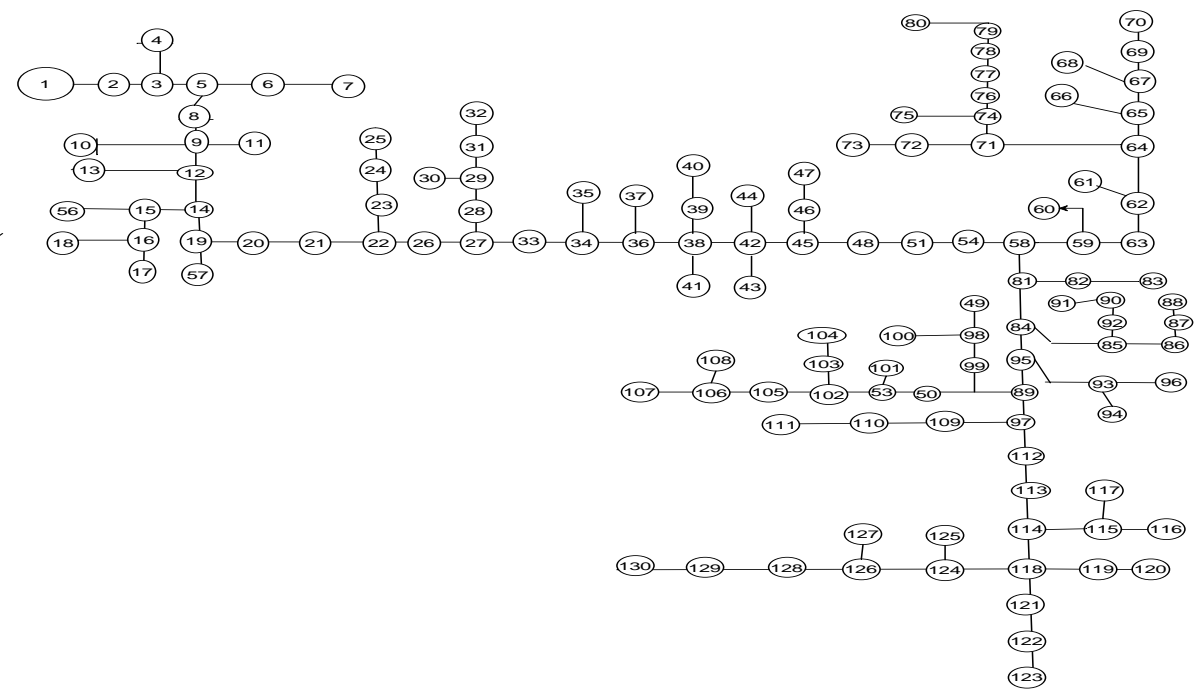

Fig 3: 130 bus Radial Distribution system, Jamwaramgarh, Jaipur 
TABLE III. DG Allocation on 130bus System Jamawaramgarh at Different Load Levels

\begin{tabular}{|l|l|c|c|c|}
\hline \multirow{4}{*}{} & \multirow{2}{*}{ Indices } & \multicolumn{3}{|c|}{ Load level } \\
\cline { 2 - 5 } & & $\begin{array}{c}\text { Light load } \\
\mathbf{( 0 . 5 )}\end{array}$ & $\begin{array}{c}\text { Nominal load } \\
\mathbf{( 1 . 0 )}\end{array}$ & $\begin{array}{c}\text { Heavy load } \\
\mathbf{( 1 . 6 )}\end{array}$ \\
\hline \multirow{4}{*}{ Without DG } & Power Loss in $\mathrm{kW}$ & 70 & 335 & 1217 \\
\cline { 2 - 5 } & $\mathrm{V}_{\min }$ in pu & 0.92 & 0.825 & 0.66 \\
\hline \multirow{5}{*}{ With DG } & DG size in $\mathrm{kW}$ & $120(106)$ & $210(106)$ & $300(106)$ \\
& [bus no.] & $60(115)$ & $120(115)$ & $180(115)$ \\
& & $80(119)$ & $150(119)$ & $210(119)$ \\
& & $90(122)$ & $190(122)$ & $240(122)$ \\
& & $130(128)$ & $270(128)$ & $340(128)$ \\
\cline { 2 - 5 } & Total DG size in $\mathrm{kW}$ & 480 & 940 & 1270 \\
\cline { 2 - 5 } & Real Power losses in $\mathrm{kW}$ & 32.2 & 141.6 & 461 \\
\cline { 2 - 5 } & Min. bus voltage in p.u. & 0.96 & 0.9161 & 0.84 \\
\cline { 2 - 5 } & \% Loss reduction & $\mathbf{5 4 \%}$ & $\mathbf{5 7 . 7 \%}$ & $\mathbf{6 2 . 2 \%}$ \\
\hline
\end{tabular}

Table 3 shows the result of practical system with and without DG allocation at different load. The percentage power loss reductions are 54\%,57.7\% and $62.2 \%$ at light, nominal and heavy load level. The voltage profile before and after DG placement at nominal load level is shown in figure 4.

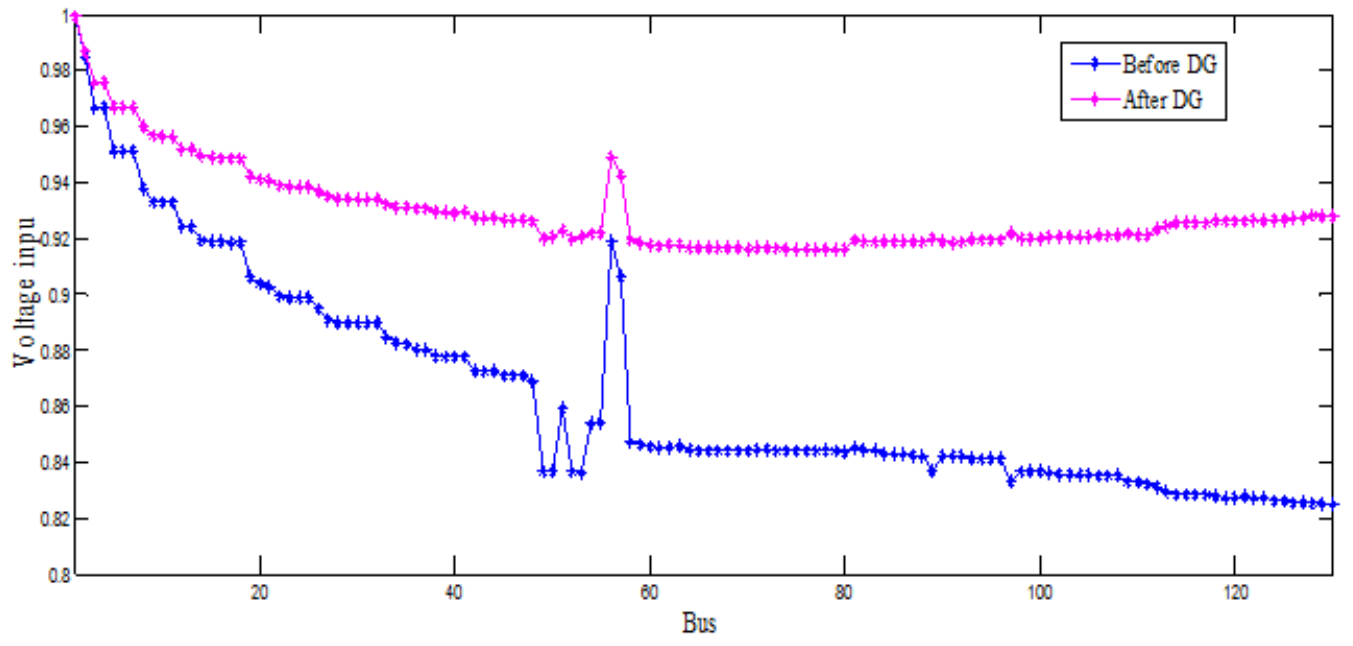

Figure 4: Voltage profile of 130 bus system before and after DG allocation (nominal load)

\section{CONCLUSION}

In this paper a novel technique has been proposed to find out optimal site and size of multiple DG units in order to reduce distribution losses. A Power Voltage Sensitivity Constant (PVSC) has been formulated to solve the problem. The level of DG penetration is also considered in a range of $0-50 \%$ of total system load. A novel index (DGPI) is also proposed which incorporates level of DG penetration and \% reduction in real power losses. The proposed technique is experienced on IEEE 33 bus standard system and 130 bus real distribution systems. The test results are compared with latest proposed algorithm and found better in terms of DGPI value. The results of real system are also promising.

\section{REFERENCES}

[1] G. Levitin, "Optimal Capacitor Allocation in Distribution Systems Using a Genetic Algorithm and a Fast Energy Loss Computation Technique", IEEE Transaction on power delivery, Vol 15, No2, April 2000.

[2] Kyu-Ho Kim, Yu-Jeong Lee, Sang-Bong Rhee, Sang-Kuen Lee and Seok-Ku You, "Dispersed generator placement using fuzzy-GA in distribution systems," Power Engineering Society Summer Meeting, 2002 IEEE , vol.3, pp.1148,1153, Jul. 2002.

[3] M. Gandomkar, M. Vakilian and M. Ehsan, "Optimal distributed generation allocation in distribution network using hereford ranch algorithm," Electrical Machines and Systems, 2005. ICEMS 2005. Proceedings of the Eighth International Conference on, vol.2, pp.916-918, Sept. 2005.

[4] N. Acharya, P. Mahat and N. Mithulananthan, "An analytical approach for DG allocation in primary distribution network," International Journal of Electrical Power \& Energy Systems, vol. 28, no. 10, pp. 669-678, 2006.

[5] S. Kamalinia, "A combination of MADM and genetic algorithm for optimal DG allocation in power systems", Universities Power Engineering Conference, 2007. UPEC 2007. 42nd International, Sept. 2007. 
[6] A. D. T. Le, M. A. Kashem, M. Negnevitsky and G. Ledwich, "Optimal distributed generation parameters for reducing losses with economic consideration," Power Engineering Society General Meeting, 2007. IEEE, pp.1, 8, 24-28 June 2007.

[7] Deependra Singh, Devender Singh, and K. S. Verma "GA based Optimal Sizing \& Placement of Distributed Generation for Loss Minimization" World Academy of Science, Engineering and Technology 35, 2007.

[8] M. Abbagana, G. A. Bakare, and I. Mustapha "Optimal Placement and Sizing of a Distributed Generator in a Power Distribution System Using Differential Evolution" Proceedings of the 1st International Technology, Education and Environment Conference African Society for Scientific Research (ASSR) 2010.

[9] M. Sedighi, A. Igderi and A. Parastar, "Sitting and sizing of distributed generation in distribution network to improve of several parameters by PSO algorithm," Presented at IPEC, 2010 Conference Proceedings, 2010.

[10] S. Nawaz, Md. Imran, Avadhesh Sharma, Anjali Jain, "Optimal Feeder Reconfiguration and DG Placement in Distribution Network" International Journal of Applied Engineering Research, Volume 11, Number 7 (2016) pp 4878-4885

[11] Rajkumar Viral , D.K. Khatod, "An analytical approach for sizing and siting of DGs in balanced radial distribution networks for loss minimization" Electrical Power and Energy Systems 67 (2015) 191-201

[12] Attia El-Fergany, "Study impact of various load models on DG placement and sizingusing backtracking search algorithm" Applied Soft Computing 30 (2015) 803-811

[13] M.E. Baran and F.F.Wu, "Network reconfiguration in distribution systems for loss reduction and load balancing", IEEE Trans. Power Del.,, vol. 4 no. 2 pp. 1401-1407, April 1989.

[14] Sandeep Kaur, Ganesh Kumbhar, Jaydev Sharma "A MINLP technique for optimal placement of multiple DG units in distribution systems" Electrical Power and Energy Systems 63 (2014) 609-617.

[15] Satish Kansal , Vishal Kumar , Barjeev Tyagi "Hybrid approach for optimal placement of multiple DGs of multiple types in distribution networks" Electrical Power and Energy Systems 75 (2016) 226-235.

[16] Suresh Kumar Sudabattula, Kowsalya M "Optimal allocation of solar based distributed generators in distribution system using Bat algorithm" Perspectives in Science (2016) 8, 270-272

[17] K.R. Devabalaji, K. Ravi "Optimal size and siting of multiple DG and DSTATCOM in radial distribution system using Bacterial Foraging Optimization Algorithm” Ain Shams Engineering Journal (2016) 7, 959-971

\section{AUTHORS PROFILE}

\begin{tabular}{|l|l|}
\hline & $\begin{array}{l}\text { Sarfaraz Nawaz was born in Jaipur, Rajathan, India. He received the B.E. } \\
\text { degree from the Rajasthan University, Jaipur, in } 2005 \text { and M.Tech. degree from } \\
\text { MNIT, Jaipur, in 2010. He is currently pursuing the Ph.D. degree from } \\
\text { Poornima University, Jaipur and also working as Associate Professor at Swami } \\
\text { Keshvanand Institute of Technology management and Gramothan, Jaipur. His } \\
\text { research areas include applications of power distribution automation problems, } \\
\text { Distributed Generation problems etc. }\end{array}$ \\
\hline $\begin{array}{l}\text { Dr. Ajay Kumar Bansal was born in Jaipur, Rajathan, India. He received } \\
\text { M.Tech. and PhD degree from MNIT, Jaipur. He is currently working as } \\
\text { Professor in Poornima University, Jaipur. His research areas include designing } \\
\text { of transmission and distribution system, Power Electronics Devices, Distributed } \\
\text { Generation problems etc }\end{array}$ \\
\hline $\begin{array}{l}\text { Dr. M.P. Sharma was born in Jaipur, Rajathan, India. He received M.Tech. } \\
\text { and PhD degree from MNIT, Jaipur. He is currently working as Assistant } \\
\text { Engineer in RVPL, Jaipur. His research areas include designing of } \\
\text { transmission and distribution system, FACTS Devices, Distributed Generation } \\
\text { problems etc. }\end{array}$ \\
\hline
\end{tabular}

